\title{
Pocket Guide to Ocular Oncology and Pathology, Grossniklaus H E, Bergstrom C, Baker Hubbard G, Wells J R, Singh A. ISBN: 978-3-642-28911-8 Springer
}

\author{
Sarah E. Coupland $\cdot$ Svetlana Cherepanoff
}

Received: 29 May 2014 / Accepted: 3 June 2014 / Published online: 20 June 2014

(C) Springer-Verlag Berlin Heidelberg 2014

All would agree how vitally important it is for pathologists and other specialists to speak a common language when describing and discussing tumours, and when discussing specimen transport and interpretation. This is why this new "Pocket Guide to Ocular Oncology and Pathology" from Hans Grossniklaus is so welcoming and a timely addition to the ophthalmic pathology literature: it furthers this bridging between ocular oncologists and the pathology laboratory.

The Sections in the Guide are organised systematically as follows: Part 1 - Basic Principles and Techniques; Part II Conjunctival and Corneal Tumors; Part III - Retinal, RPE and Ciliary Epithelial Tumors; Part IV - Retinal Tumors; Part V Uveal Tumors: Non-Melanocytic; Part VI - Uveal Tumors: Nevus and Melanoma; Part VII - Optic Nerve Tumors and Phakomatoses.

Each chapter is well-structured and all information is concisely stated under the following subheadings - Synonyms, Definition, Etiology, Clinical Presentation, Diagnosis, Pathology, Differential Diagnosis, Prophylaxis, Therapy, Epidemiology, Cross References, and Further Reading. Such a structure enables the student to revise intensely prior to theoretical and practical exams. Most chapters contain colour illustrations, schematic figures, and/or pastel-colored tables that highlight the main points made within the text. Each chapter is accompanied by a reasonably updated list of references, which are listed alphabetically. The book would be especially useful to surgeons, pathologists, and radiologists practicing in less subspecialised institutions, particularly to those still in training.

We have a few quibbles and suggestions to the authors when they consider the next iterations of this book. These are the following:

S. E. Coupland $(\bowtie) \cdot$ S. Cherepanoff

Department of Molecular and Clinical Cancer Medicine, University of Liverpool, Liverpool, UK

e-mail: s.e.coupland@liverpool.ac.uk
1. For the book truly to be a "pocket guide" we suggest that its formatting is smaller, so that it does fit into the typical coat or jacket pocket. Perhaps a soft or water-resistant cover should also be considered.

2. Changes in font or font color and dividing lines between parts would make the "Contents" section easier to navigate.

3. An index at the back of the book would be appropriate to make for even greater ease of reference to the Guide's contents.

4. Listing the authors and affiliations on the first page of each chapter is repetitive. This information is already present in the "Contributors" sections, and takes up valuable space.

5. A summary of AJCC TNM criteria for all malignant tumours, similar to those presented in the Washington Manual of Surgical Pathology, would be helpful.

6. Improvement in the resolution in some of the images is required in the next edition - e.g. Figures 14.2 19.2, 36.2, $37.3,39.2,53.1(\mathrm{~d})$. Is the image for 75.4 correct? We would suggest it shows a haemangioblastoma, not a plexiform neurofibroma as indicated in the Legend.

7. The references are not as up-to-date as one might expect in some of the Chapters.

8. In Chapter 33, the authors use the unusual term "primary lymphoma of the central nervous system-ophthalmic" (PCNSL-O). It is hoped that the future editions will discourage use of this term, which is not really in line with current literature or terminology. More suitable would be the term "vitreoretinal lymphoma," for reasons discussed in the reviews mentioned below ${ }^{1,2}$.

In summary, we can thoroughly recommend Pocket Guide to Ocular Oncology and Pathology, as an educational tool and particularly as a standard reference text for trainees in ophthalmology and those in surgical pathology with an interest in the neoplasms of the eye and the ocular adnexa. 